\title{
Condução de um caso de infecção de sítio operatório de cavidade peritoneal em uma Unidade Básica de Saúde no início da Pandemia por COVID-19 no município de Bocaina do Sul - SC
}

Conducting a case of infection of the peritoneal cavity surgical site in a Basic Health Unit at the beginning of the Pandemic by COVID-19 in the city of Bocaina do Sul - SC Realización de un caso de infección del lecho quirúrgico de la cavidad peritoneal en una Unidad Básica de Salud al inicio de la Pandemia por COVID-19 en la ciudad de Bocaina do Sul - SC

Bruno Medeiros ${ }^{1}{ }^{(1)}$

${ }^{1}$ Prefeitura Municipal de Bocaina do Sul-SC

\begin{abstract}
Introduction: The world was surprised by COVID - 19 Pandemic, a viral infection caused by SARSCOV-2, which started in Wuhan, People's Republic of China, in December 2019. In addition to this new disease, the entire Brazil continued to deal with other diseases that have plagued our patients for decades. We present a case report of infection of the peritoneal cavity operative site that occurred at the beginning of the Pandemic by COVID-19 in Brazil. Case Report: patient who underwent radical prostatectomy, evolved with infection of the operative site 30 days after surgery, had a collection in the abdominal wall that was interconnected with pelvis cavity that could be drained with a wall drain. Discussion: The rate of infection of the operative site can reach up to $5 \%$ in radical prostatectomy surgeries, which is an acceptable rate. The beginning of the Pandemic in Brazil prevented the patients from returning to the big hospitals to some extent, either due to fear or uncertainty. Conclusion: We present a case of infection of the surgical site that coincided with the beginning of the Coronavirus Pandemic in Brazil that can be treated in a Basic Health Unit.
\end{abstract}

Keywords: Coronavirus; Surgery; Infections.

\section{Resumo}

Introdução: O mundo foi surpreendido pela pandemia COVID-19, uma infecção viral causada pelo SARS-COV-2, iniciada em Wuhan, na República Popular da China, em dezembro de 2019. Além dessa nova doença, o Brasil inteiro continuou a lidar com outras doenças que atormentam nossos pacientes há décadas. Apresentamos um relato de caso de infecção do sítio operatório da cavidade peritoneal que ocorreu no início da Pandemia pelo COVID-19 no Brasil. Relato De Caso: paciente submetido a prostatectomia radical, evoluiu com infecção do sítio operatório 30 dias após a cirurgia, possuía coleção na parede abdominal e na pelve interconectadas entre si, que poderia ser drenada com dreno de parede. Discussão: A taxa de infecção do sítio operatório pode chegar a $5 \%$ em cirurgias de prostatectomia radical, que é uma taxa aceitável. O início da pandemia no Brasil impediu que os pacientes retornassem aos grandes hospitais, de certa forma, devido ao medo ou à incerteza. Conclusão: Apresentamos um caso de infecção do sítio cirúrgico que coincidiu com o início da pandemia de coronavírus no Brasil que pode ser tratada em uma unidade básica de saúde.

Palavras-chave: Coronavirus; Cirurgia; Infecções.

Como citar: Medeiros B. Condução de um caso de infecção de sítio operatório de cavidade peritoneal em uma Unidade Básica de Saúde no início da Pandemia por COVID-19 no município de Bocaina do Sul - SC Rev Bras Med Fam Comunidade. 2021;16(43):2664. https://doi.org/10.5712/rbmfc16(43)2664
Autor correspondente: Bruno Medeiros E-mail: brunaojose@bol.com.br Fonte de financiamento: não se aplica. Parecer CEP: não se aplica Procedência: não se aplica Avaliação por pares: externa. não encomendado. Recebido em: 05/08/2020. Aprovado em: 19/03/2021. 


\section{Resumen}

introducción: El mundo se sorprendió con la pandemia COVID-19, una infección viral causada por el SARS-COV-2, que se inició en Wuhan, en la República Popular China, en diciembre de 2019. Además de esta nueva enfermedad, todo Brasil continuó lidiando con otras enfermedades que han afectado a nuestros pacientes durante décadas. Presentamos el reporte de un caso de infección del sitio operatorio de la cavidad peritoneal que ocurrió al inicio de la Pandemia por COVID-19 en Brasil. Relato De Caso: paciente que fue sometido a prostatectomía radical, desarrolló una infección del sitio operatorio 30 días después de la cirugía, tenía una colección en la pared abdominal y pelvis interconectada entre sí, que podía drenarse con un drenaje mural. Discusión: La tasa de infección del sitio operatorio puede llegar al $5 \%$ en las cirugías de prostatectomía radical, lo que es una tasa aceptable. El inicio de la pandemia en Brasil impidió que los pacientes regresaran a los grandes hospitales, en cierto modo, por miedo o incertidumbre. Conclusión: Presentamos un caso de infección del sitio quirúrgico que coincidió con el inicio de la pandemia de coronavirus en Brasil que puede ser tratado en una unidad básica de salud.

Palabras clave: Coronavirus; Cirugía; Infecciones.

\section{Introdução}

O mundo foi surpreendido pela Pandemia do COVID - 19, uma infecção viral causada pelo SARSCOV-2, a qual se iniciou em Wuhan, província de Hubei na república da China, em dezembro de $2019^{1}$. Uma doença com alto grau de disseminação entre os seres humanos e que se alastrou rapidamente para todos os continentes e chegou ao Brasil entre Janeiro e Fevereiro de 2020, causando medo, incertezas e fechamento de vários serviços considerados não essenciais.

Além dessa nova doença o Brasil inteiro continuou a lidar com outras doenças que já acometiam nossos pacientes há décadas, como a infecção do sítio operatório (ISO) que é algo frequente nos hospitais brasileiros, sendo responsáveis por 14 a $16 \%$ das infecções em pacientes hospitalizados do nosso país².

Diante da situação dessa nova doença acometendo os primeiros pacientes em território nacional, apresentamos um relato de caso de infecção de sítio operatório de cavidade pelviperitoneal que ocorreu no início da Pandemia pelo COVID-19 no Brasil conduzida em Unidade Básica de Saúde do Município de Bocaina do Sul -SC.

\section{Relato de Caso}

Paciente do sexo masculino, 61 anos, veio a nossa Unidade Básica de Saúde dia 11/02/2020, nesta ocasião encontrava-se no $30^{\circ}$ dia de pós-operatório de prostatectomia radical aberta para neoplasia de próstata com suspeita de malignidade, apresentava sinais de flogose em região da ferida operatória com cerca de $3 \mathrm{~cm}$ de halo de cada lado, saída de secreção serosanguinolenta por pequeno orifício e febre de $38^{\circ} \mathrm{C}$ (Figura 1).

Foi iniciado Cefalexina 500mg de 6/6 horas, realizado ampliação da drenagem do seroma. Solicitou-se ultrassom de parede abdominal e de abdome total bem como foram mantidos os cuidados de enfermagem e a confecção de curativos diários.

Paciente obteve melhora parcial dos sintomas e sinais flogísticos, mas voltou a ter febrícula de $37,8^{\circ} \mathrm{C}$ no dia 16/02/2020. Retornou na mesma data já com resultado do ultrassom de parede abdominal e abdome total que revelava uma coleção na cavidade pélvica com $54 \mathrm{~cm}^{3}$ em comunicação com uma coleção em parede abdominal com $38 \mathrm{~cm}^{3}$ (Figura 2).

Paciente foi submetido à drenagem da coleção de parede abdominal com dreno de Waterman (confeccionado com uma sonda de Nelaton que é introduzida dentro de um dreno de Penrose) posicionado no espaço subcutâneo. Foi mudado o antibiótico para Ciprofloxacino 1g/dia e Metronidazol 500mg 8/8 horas que permaneceu por 14 dias e em seguida foi solicitado ultrassom de controle.

Paciente retornou ao hospital de origem, onde foi orientado que continuasse o tratamento ora iniciado na Unidade Básica de Saúde. 
Retornou no dia 10/03/2020 com ultrassom de controle que mostrava uma diminuição da coleção pélvica para $52,2 \mathrm{~cm}^{3}$ e da parede para $12,9 \mathrm{~cm}^{3}$, dreno bem posicionado na coleção da parede que se comunicava com a coleção interna (Figura 3).

Realizou mais outro ultrassom no dia 31/03/2020 com coleção pélvica e de $20 \mathrm{~cm}^{3}$ e coleção de parede já solucionada, ou seja, com $00 \mathrm{~cm}^{3}$.

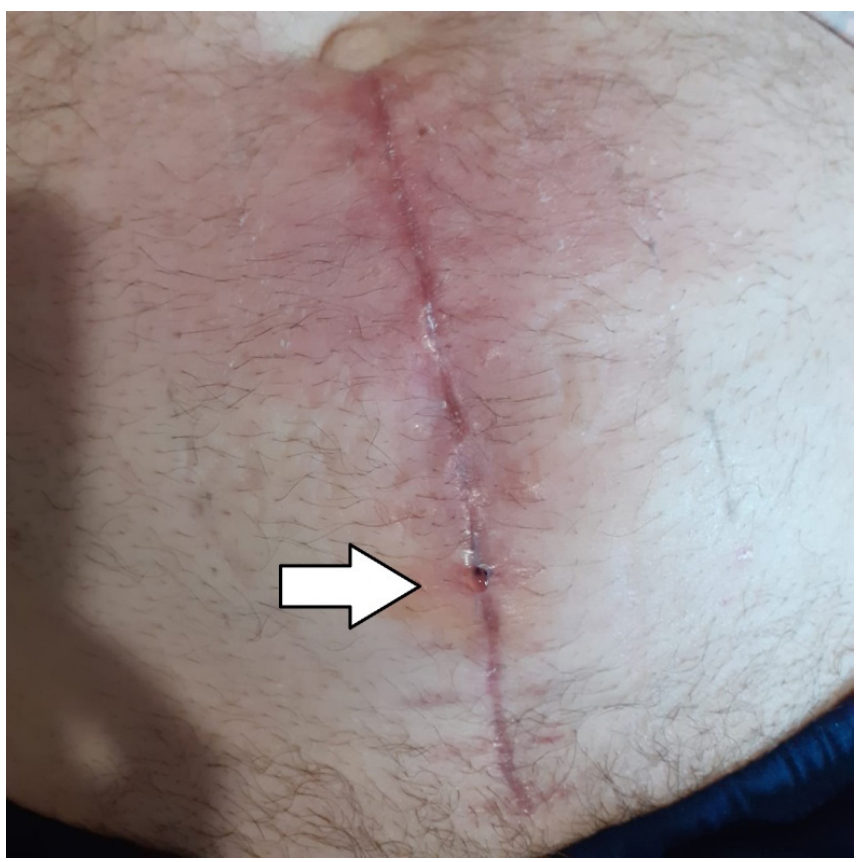

Figura 1. Seta indica o local de saída de secreção serosanguinolenta.

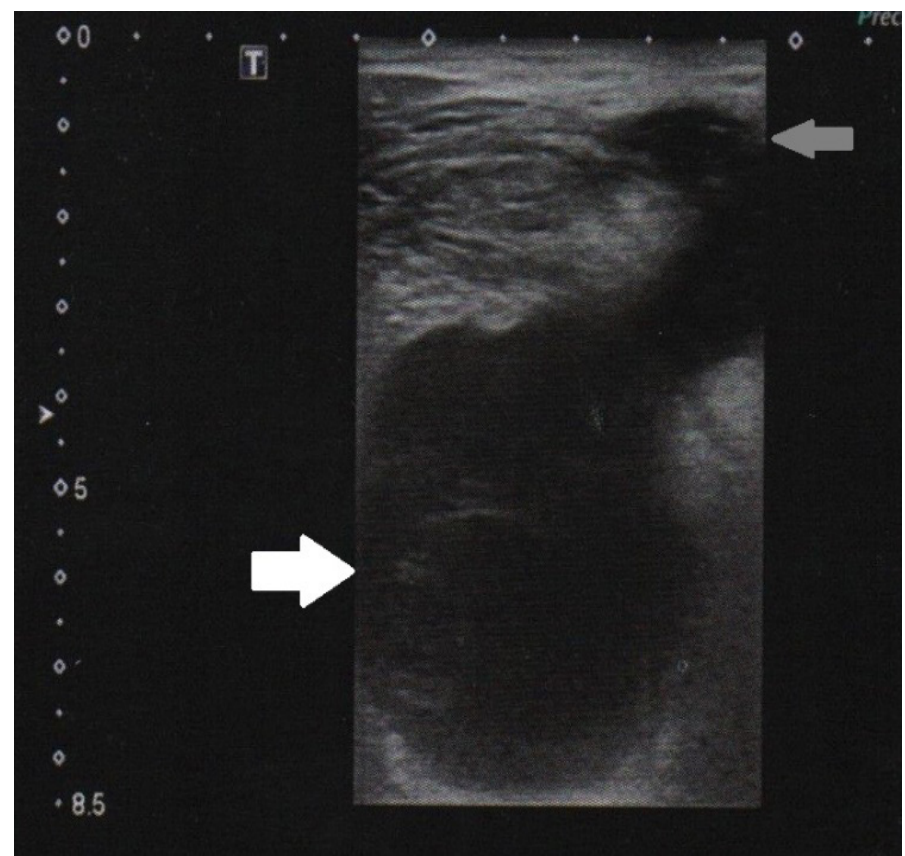

Figura 2. Coleção pélvica (Seta branca), coleção da parede (Seta cinza).

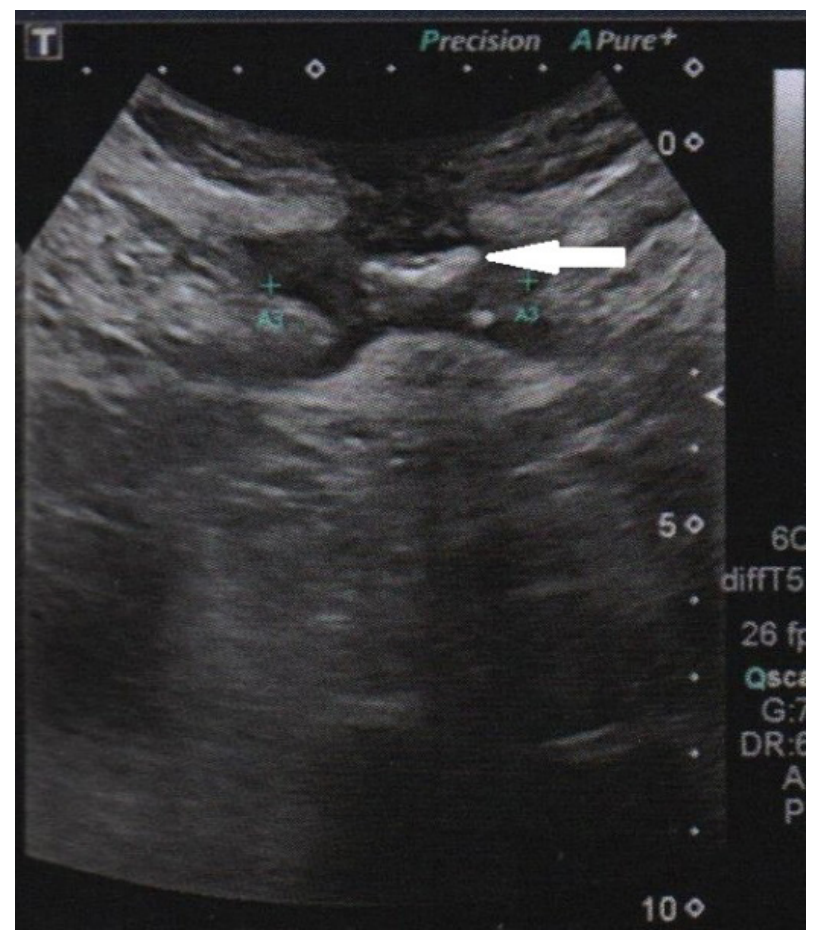

Figura 3. Dreno bem posicionado na coleção da parede. 
Optado por troca do dreno de Waterman por outro dreno igual, mas com materiais novos, que foi confeccionado da mesma forma e posicionado no espaço subcutâneo.

Realizou-se mais dois ultrassons de controle em 15/04/2020 que revelava somente coleção pélvica de $9,2 \mathrm{~cm}^{3}$ e em 04/05/2020 com completa remissão do abcesso intracavitário.

Durante todo esse período o paciente foi acompanhado semanalmente na Unidade Básica de Saúde pela equipe médica e diariamente pela equipe de enfermagem através da realização de curativos domiciliares.

\section{Discussão}

As infecções do sítio operatório podem se manifestar até 30 dias após a cirurgia ou em até 90 se houver implantes associados. Podem ser classificadas de acordo com o grau de profundidade da infecção:

a) incisional superficial que acomete pele e tecido celular subcutâneo;

b) incisional profunda que acomete planos miofasciais;

infecção de órgão e/ou cavidade (peritoneal, pleural, mediastinal).

O índice de infecção de sítio operatório pode chegar até $5 \%$ em cirurgias de prostactectomia radical e são tidos como valores aceitáveis diante a complexidade do procedimento e abertura do trato urinário de modo controlável ${ }^{4,5}$.

A infecção do sítio operatório é considerada a infecção hospitalar mais comum em pacientes cirúrgicos, aumenta o tempo de internação de 7 a 11 dias e o risco de mortalidade de duas a 11 vezes. Em alguns serviços já foi observado internação de 20 a 148 dias com tempo médio de 49,2 dias ${ }^{6}$.

Nosso Paciente ficou em acompanhamento na UBS por 80 dias.

O início da Pandemia por Coronavírus no Brasil gerou medos e incertezas o que levou muitos pacientes a retardarem a ida aos grandes centros e grandes hospitais com receio de contraírem a nova doença.

O tratamento de infecções de sítio operatório de órgão ou cavidade geralmente é conduzido em unidades hospitalares, nesse caso apresentado o início da Pandemia coincidiu com o início dos sintomas prejudicou em parte o tratamento na unidade hospitalar ${ }^{7}$.

O tratamento por sua vez foi realizado em uma Unidade Básica de Saúde que teve como principal vantagem o acompanhamento de perto do paciente e em seu próprio nosocômio, mas teve como desvantagens o uso de antibioticoterapia empírica e a drenagem de abscesso ás cegas, ou seja, sem o auxílio do ultrassom no momento do procedimento.

Mesmo assim a comunicação entre as coleções pélvica e da parede abdominal possibilitou o tratamento com um único dreno posicionado no espaço subcutâneo e evitou o deslocamento do paciente de uma pequena cidade a um centro de referência e submeter-se ao risco de contrair COVID -19 tão temido sobretudo naqueles primeiros dias.

\section{Conclusão}

Apresentamos um caso de infecção do sítio operatório de cavidade que coincidiu com o início da Pandemia por Coronavírus no Brasil. Um achado ultrassonográfico de comunicação entre coleções intra cavitária e de parede permitiu que um procedimento simples como a drenagem do espaço subcutâneo associado ao uso de antibióticos orais pudesse resolver todo o problema e evitou que o paciente fosse conduzido a um grande centro num momento em que todos estavam com receio de contrair uma doença ora desconhecida e temida por todos. 
Procedimentos simples bem indicados mesmo e um Unidade Básica de Saúde podem resolver grandes problemas.

\section{Conflitos de interesse}

O autor declara não haver quaisquer tipos de conflito de interesse.

\section{Referências:}

1. Novel Coronavirus Pneumonia Emergency Response Epidemiology Team. Vital surveillances: the epidemiological characteristics of an outbreak of 2019 novel coronavirus diseases. (COVID-19)—China, 2020. China CDC Weekly. Chinese Center for Disease Control and Prevention CCDC Weekly. 2020; 2 (811): 8119 DOI: https://doi.org/10.46234/ccdcw2020.032

2. Agencia Nacional de Vigilância Sanitária. Medidas de Prevenção de Infecção Relacionada à Assistência à Saúde. Série Segurança do Paciente e Qualidade em Serviços de Saúde 2. ed. [Internet]. Brasília (DF): Ministério da Saúde; 2017[cited 2017 Ago 12]. Available from: http://portal.anvisa.gov.br/documents/33852/271855/Medidas+de+Preven\%C3\%A7\%C3\%A3o+de+Infec\%C3\%A7\%C3\%A3o+Relaci on ada+\%C3\%A0+Assist\%C3\%AAncia+\%C3\%A0+Sa\%C3\%BAde/6b1 6dab3-6d0c-4399-9d84-141d2e81c809

3. MINISTÉRIO DA SAÚDE (Brasil). Agência Nacional de Vigilância Sanitária. Sítio Cirurgico. In: Sítio Cirurgico. Brasil, 1 maio 2009. Disponível em: http://www.anvisa.gov.br/servicosaude/manuais/criterios_nacionais_ISC.pdf. Acesso em: 19 jun. 2020.

4. Gillitzer R, Thuroff JW. Relatives advantages and disadvantages of radical perineal prostatectomy versus radical retropubic prostatectomy. Criticals Reviews in Oncology/Hematology. 2002;43(2):167-90. DOI: https://doi.org/10.1016/S1040-8428(02)00016-1

5. Sullivan LD, Weir MJ, Kinahan JF, Taylor D. A comparison of the relative merits of radical perineal and radical retropubic prostatectomy. BJU Int. 2000;85(1):95-100. DOI: https://doi.org/10.1046/j.1464-410x.2000.00405.x

6. Anderson DJ, Podgorny K, Berríos-Torres SI, Bratzler DW, Dellinger EP, Greene, et al. Strategies to Prevent Surgical Site Infections in Acute Care Hospitals: 2014 Update. Infect Control Hosp Epidemiol. 2014;35(6):605-27. DOI: https://doi.org/10.1086/676022

7. Badia JM, Casey AL, Petrosillo N, Hudson PM, Mitchell SA, Crosby C. Impact of surgical site infection on healthcare costs and patient outcomes: a systematic review in six European countries. J Hosp Infect. 2017;96(1):1-15. PMID:28410761 DOI: https://doi.org/10.1016/j. jhin.2017.03.004 